\title{
Using a Web-Based App to Improve Hand Hygiene Compliance Rates
}

Benjamin Rome, MD; Haipeng Zhang, DO; Adam Landman, MD

Brigham and Women's Hospital, Boston, MA, United States

Corresponding Author:

Haipeng Zhang, DO

Brigham and Women's Hospital

Boston, MA,

United States

Phone:

Email: $\underline{\text { hzhang37@mgh.harvard.edu }}$

\section{Abstract}

Background: Our institution has prioritized improving hand hygiene rates. Empty or broken alcohol-based hand sanitizer dispensers are a barrier to efficient hand hygiene practices. One barrier is the lack of modalities for employees to alert when a dispenser is empty or broken.

Objective: We hypothesize that adding predefined QR code functionality to an existing web-based service repair application for staff will facilitate increased alerts about empty hand sanitizer dispensers.

Methods: The FixIt app is a Web-based application that enables staff at our academic hospital to report issues to environmental services including when supplies are broken, if rooms are dirty, or if an item in a room needs to be restocked. However, users must type a free text description of the problem to report it. We propose adding functionality to allow users to scan a QR code with their SmartPhone or enter a unique text code that will be labeled on each hand sanitizer dispenser. This unique code will be directly associated to a specific dispenser and alert the environmental services department to the exact dispenser to fix or replace, thereby reducing the number of empty or broken dispensers. To measure the scope of the problem, we evaluated the functionality of all hand sanitizer dispensers in public spaces on patient wards and hallways in our institution at a single point in time and then sequentially over a course of 48 hours. We also evaluated the usage of the existing FixIt application and categorized the types of requests that FixIt has processed to date.

Results: Out of 535 hand sanitizer dispensers, forty-nine dispensers (9.2\%) were not functional on our baseline evaluation. After 12 hours, 23 of these non-functional dispensers (46.9\%) had not yet been fixed or refilled. After 48 hours, 17 dispensers $(34.7 \%)$ were still not functioning. The existing FixIt application without QR codes was deployed in September 2017. Since then, the application has generated over 400 FixIt requests via manual text-entry form. Of those requests, $17 \%$ were categorized as "repair/restock" requests.

Conclusions: We propose adding a QR-based feature to an existing Web-based application to streamline and facilitate repetitive tasks such as reporting empty or broken hand sanitizer dispensers. Our preliminary results suggest that users are already willing to utilize a manual form via a Web application to request restocking or repair of items within the hospital. We think that lowering the barrier for reporting by utilizing QR codes may improve usage rates of this feature. Our next steps are to implement a small pilot of the FixIt QR code evaluate uptake and utilization.

(iproc 2018;4(2):e11812) doi: $10.2196 / 11812$

\section{KEYWORDS}

electronic symptom reporting; hand-washing; quality indicators 
Edited by T Hale; this is a non-peer-reviewed article. Submitted 02.08.18; accepted 29.08.18; published 17.09.18.

Please cite as:

Rome B, Zhang H, Landman A

Using a Web-Based App to Improve Hand Hygiene Compliance Rates

iproc 2018;4(2):e11812

URL: http://www.iproc.org/2018/2/e11812/

doi: $\underline{10.2196 / 11812}$

PMID:

(C)Benjamin Rome, Haipeng Zhang, Adam Landman. Originally published in Iproceedings (http://www.iproc.org), 17.09.2018. This is an open-access article distributed under the terms of the Creative Commons Attribution License (https://creativecommons.org/licenses/by/4.0/), which permits unrestricted use, distribution, and reproduction in any medium, provided the original work, first published in Iproceedings, is properly cited. The complete bibliographic information, a link to the original publication on http://www.iproc.org/, as well as this copyright and license information must be included. 